International Journal of Social Science and Economic Research

ISSN: 2455-8834

Volume:06, Issue:03 "March 2021"

\title{
GENDER INEQUALITY IN INDIA: STATUS AND DETERMINANTS
}

\author{
Devinder S Hooda \\ Devinder Singh Hooda teaches Economics at Indira Gandhi University, Meerpur, Rewari (Haryana)-India \\ DOI: 10.46609/IJSSER.2021.v06i03.020 URL: https://doi.org/10.46609/IJSSER.2021.v06i03.020
}

\begin{abstract}
Gender equality is a fundamental human right which entitles everyone to enjoy all the basic facilities with equality and dignity. But inequality in gender proficiencies and their authorities distribution produce variations among them which affects their livelihood. Despite of several measures to bring gender equality, India still measures high gaps in basic facilities like education, health and labour force participation. There are several cultural and social factors measured behind it for delivering such dissimilarities like patriarchal system, old age support from son, elderly care and high desire for sons in the family. Keeping in view women's unequal status in India, this paper aims to underline determinants of women inadequacy across basic indicators of development. Though there are several other measures too for ascertaining the degree of gender inequalities but as per the need of this study, the indicators such as access to education, health, economic participation and potency of decisions making among the marginalised groups are being analysed. The level of disproportions in these parametric framework replicates all those basic areas of propensities inadequacy that have an adverse effect on women empowerment, country's productivity, distribution, efficiency and economic growth.
\end{abstract}

Keywords: Gender parity, Health and Education, Health deprivation, Marginalized, SouthAsian countries

\section{Introduction}

Gender inequality continues to be a major concern to discuss despite of high economic growth achieved by the country. Women everywhere devote their notable time on uneconomic undertakings which shrink their productivity in economic terms and generates inequality. These dynamics escorted them remarkably and impose massive burden of unpaid care work on them. Apart from this they also face maternal and fertility issues, family-oriented work and cultural differences that affect them badly. The high desire for sons moreover provokes a biasness for a particular type of portfolio which compels paternities to earmark more or less coinage to children education and hence influence bequests (Davies and Zhang, 1995).It means that on the one side, 


\section{International Journal of Social Science and Economic Research}

ISSN: $2455-8834$

Volume:06, Issue:03 "March 2021"

an educated woman with a healthy regime is contemplated as the significant for family progress whereas on the other side they are disregarded in the communities in terms of offering uniformity.

Women consist of 48.5 percent of the population, means there are 35,685,539 fewer women than men across India (Census, 2011). They are the side-lined when it is a matter of decision making for crucial concerns. Despite offering equal rights to them, men dominate the society which in turn dispels women decisional authority. Moreover, female political participation is less than 15 percent in Indian parliament out of which 11.8 percent represented in Lok Sabha and 11 percent in Rajya Sabha in MPs (Economic Survey 2018). During this survey, factors such as domestic work, cultural attitudes towards women role and lack of family support are considered as leading obstacles behind preventing women from political participation in India. According to the Global Gender Gap report also (2017), India stands at 108 in global ranking out of 144 countries, accomplishes $139^{\text {th }}$ rank (score of 0.376 ) in economic participation, $112^{\text {th }}$ position (score of 0.952) in education attainment, $141^{\text {st }}$ (score of 0.942 ) in health and survival and $15^{\text {th }}$ position (score of 0.407 ) in political empowerment as per this report.

It is also measured that almost one out of five women did not receive antenatal care and more than 36 percent of women have energy deficiency in India (NFHS-3). Another setback that effect women health is the orthodox attitude to their natal, which gives rise to many other complications from their birth itself. It gives rise to difference in milk feeding frequencies, nutrition diet, absence of caretaking and prevalence of high trafficking among girl child. Sen, A. (1998), noticed that the disparities in Asian countries (India and China) as compared to American and European countries arises especially in nutritional and health caused by cultural and mechanism, traditions and values differences. Thus, the vital argument of this paper is to examine the inherent gender role and female economic status in Indian society. While keeping in view all these aspects the below-portrayed diagrams helps in providing a brief description of women health status in India and its status other South Asian Countries. Therefore, the sole objective of this paper is to study the socio-economic status of women in India via gender discrimination in Education, health and labour force participation.

\section{Health Deprivation in South Asian Countries}

According to the World Health Organisation (2013), health is a complete state of physical, mental and social wellbeing. Any kind of discrimination in health structure connected with gender influence in society. Despite of being biological advantage and higher life expectancy of female they have adverse sex ratio in India. There is an unusual shortfall of female population because of cultural dissimilarity and missing women in the country. The sex-selective abortions, 
female infanticide, inadequate healthcare and difference in nutritional status are also the crucial argument that fosters these gaps (Sen, 1992). Hence, the below-portrayed diagram helps in ascertaining a brief description of women health status in India and other South Asian Countries.

\section{Figure 1: Health Deprivation in South Asian Countries}

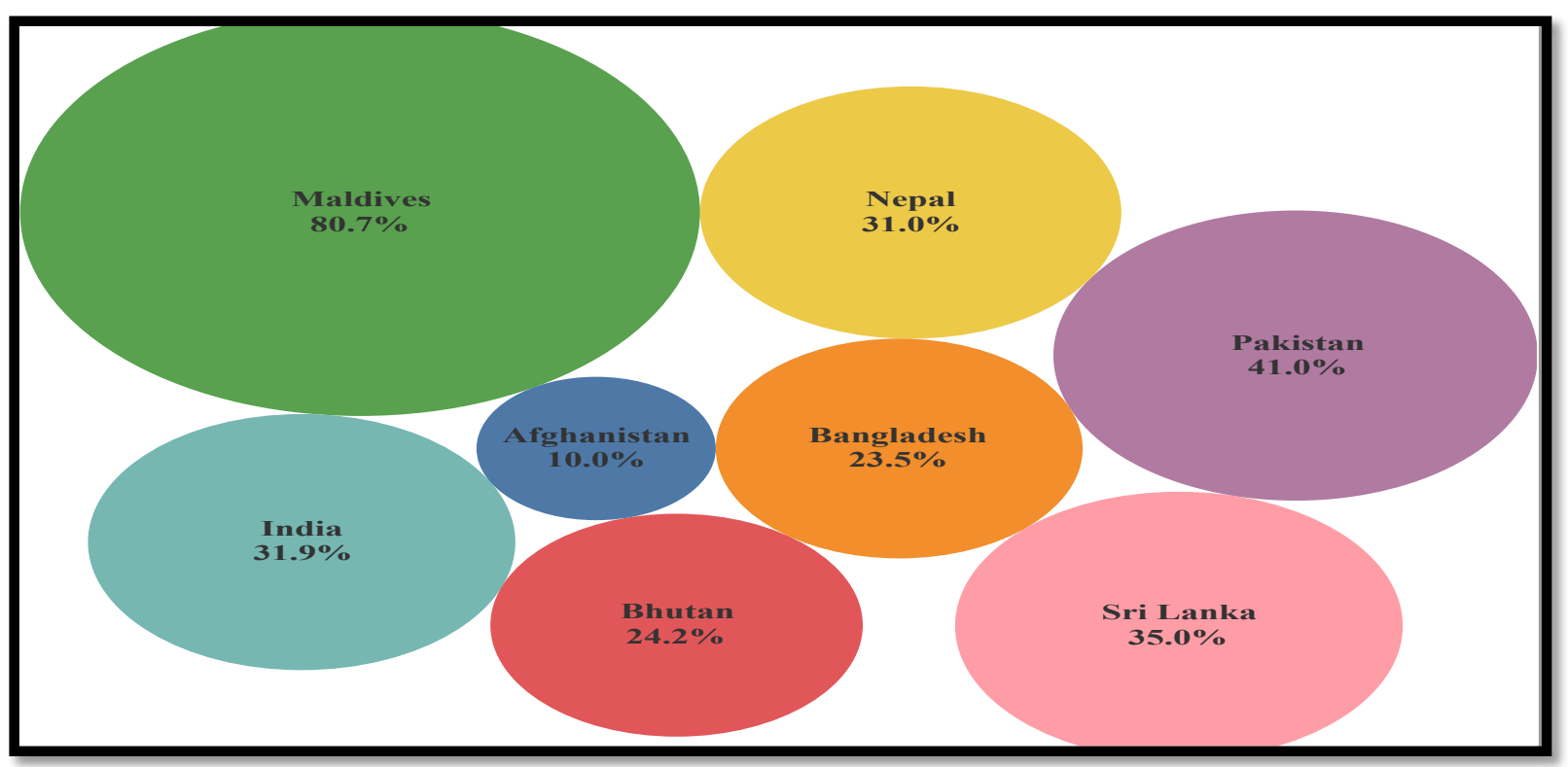

Source: HDI Report (2019) *Afghanistan missing indicator on nutrition

The above figure elevated data from the Multidimensional Poverty Index for the South Asian countries to establish comparison analysis with India. It highlights the level of deprivation in health care facilities in terms of inadequate amount of food, wellbeing and access to proper healthcare facilities. India, Nepal and Sri Lanka replicate almost the same percentage of deprived population that are affected because of the poor health care facilities accessibilities. Whereas, Nepal being a very small economy is performing well in providing health access to its people than India. Bhutan also set as an inspiration to the world where its gross happiness index approach overwhelmed its gross income index. Bhutan accounts to 24.2 percent health deprivation population over 31.9 percent underprivileged population measured in India. It is observed worse in case of women especially when they are poor and belongs to remote and underdeveloped areas. Because of the lack of mobility among them, they find it difficult to reach the health care centres and in turn upsurge the higher girl infant mortality and maternal mortality rates. Hence, from the above analysis it can be concluded that there is no such positive correlation between the higher per capita income and health outcomes for country like India. 
International Journal of Social Science and Economic Research

ISSN: 2455-8834

Volume:06, Issue:03 "March 2021"

Figure 2: Child mortality rate in South Asian Countries (per 1000 lives) (1-5 years)

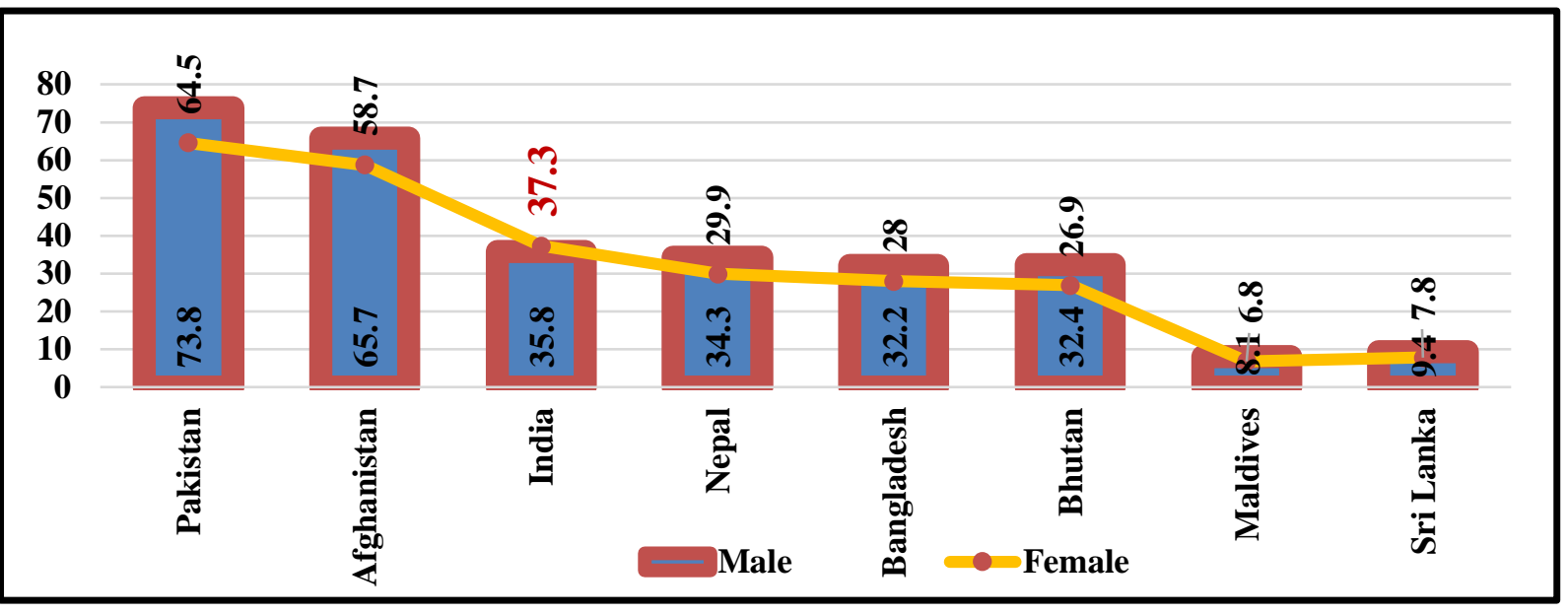

Source: World Data Atlas (2018)

Figure 3: Health Expenditure of South Asian Countries to GDP

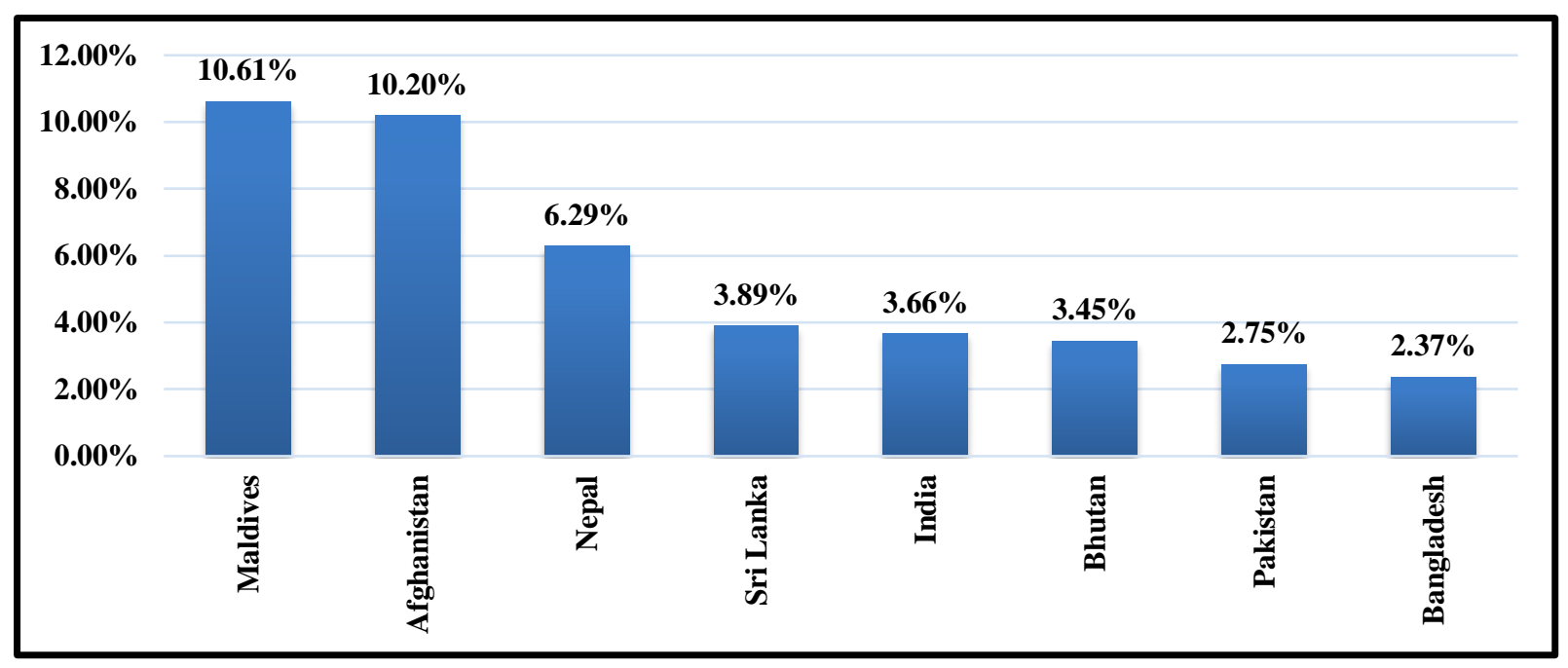

Source: World Bank, World Development Indicators (2018)

Apart from poor health outcomes in India, it measured highest gender gaps among all other countries in South Asia. Above portrayed figure underlines the condition of South Asian countries in terms of gender-based child mortality rate to reflect the intensity of discrimination perceived by them. Females are measured more biological advantaged than the survival rate males which make them less vulnerable to prenatal conditions and infections. Hence, all the South Asian countries observe the same with only one exception of India. Even the Pakistan that 


\section{International Journal of Social Science and Economic Research}

ISSN: $2455-8834$

Volume:06, Issue:03 "March 2021"

resembles the highest child mortality rate perceive 65.7 death for males over 58.7 females, means favourable to females. Same is observed with other countries too except India, their female's mortality rate is high as compared to male child. On the contrary, Sri Lanka and the Maldives have very less child mortality rate with just 7.4 and 8.6 overall. Hence, we can say that India is an alone South Asian country with a high female child mortality rate (37.3) contrary to the male child (35.8) measuring the highest gender differential country. These data are quite indicative to reflect that female in India does not enjoy the same biological advantage as men do because of high female infanticide and feticides occurrence in the coutry. It shows the ugly picture of gender biases on the name of tradition, patriarchal system and high desire for sons in every family.

To bring out deprived section of society from any form of health distress government spends enormous amount on the health sector. The above figure 3 depicts the quantum of budgetary allocation to the proportional share of their GDP. It measures an awful variation in health expenditure as a percentage of GDP across the South Asian countries. It perceived extremely low share of countries like India, Bhutan, Pakistan and Bangladesh with 3.66, 3.45, 2.75 and 2.37 percent respectively to their GDP in 2018. Whereas, Afghanistan, Maldives and Nepal are spending their considerable share to this sector with $10.20,10.61$ and 6.29 percent respectively for the same year. Despite of being an emerging countries of the world (India and Sri Lanka), these countries endorsed bottommost spending to the health sector. Reason found behind this stumpy growth in India health expenditure is perhaps the private expenditure dominant countries, which make it difficult to avail for the poor people. Whereas, Afghanistan, Maldives and Nepal regardless of low income generating countries are spending their significant share on facilitating health. Another thing that has been observed from above analysis that these same countries spending higher proportion of their GDP because they are more deprived in health overall. India on contrary has a higher prevalence of gender gap in health facilitation which indicates that it needs some specific provision for improving female health outcomes instead of spending overall on the health sector.

\section{Gender Gaps in Education}

Education is the most imperative aspect of life since it imparts knowledge and decision making power among individuals. It is not only a crucial approach to overall individual development rather an integral part of being healthy. It assists in developing self-confidence to look upon something better with sentiments and reasons behind incredible happening around them. This unsurpassed approach empowers people socially, economically, culturally and can convey better outcomes for society as a whole. Hence, education is measured significant for imparting knowledge and sophisticated socio-economic growth. It diversifies to sustainable approach as a 
potent driver of development and instrument to overcome poverty and restoring health. Effect of per capita budgetary education expenditure on literacy gap ratio turns out to be highly significant in improving literacy gap ratio (Singh D2013; Agarwal, M. 2018). It produces positive multiplier effect on the next generation, considering that an educated mother more likely to send their kids to school without any gender discrimination. It has potential to improve millions of lives, ultimately lead to more equitable distribution, strong families, better survival and child health care also (UNICEF, 2004). Investment in this sector leads to improved health, standardisation and enhanced gender consequences also as a whole. In terms of Mahatma Gandhi "educating one man, you educate one Pearson but educate women and you educate a whole civilization". Whereas, on the other side it is perceived that women spend twice as much time on the unpaid activities as the men do on an average which is a major cause of hampering women participation in education (World Economic Forum, 2018). Female still has 65.4 percent of total participation in the education system whereas men stood at 82.14 percent (Census, 2011).

Figure 4: Gender Gap in Literacy Rate among South Asian Countries

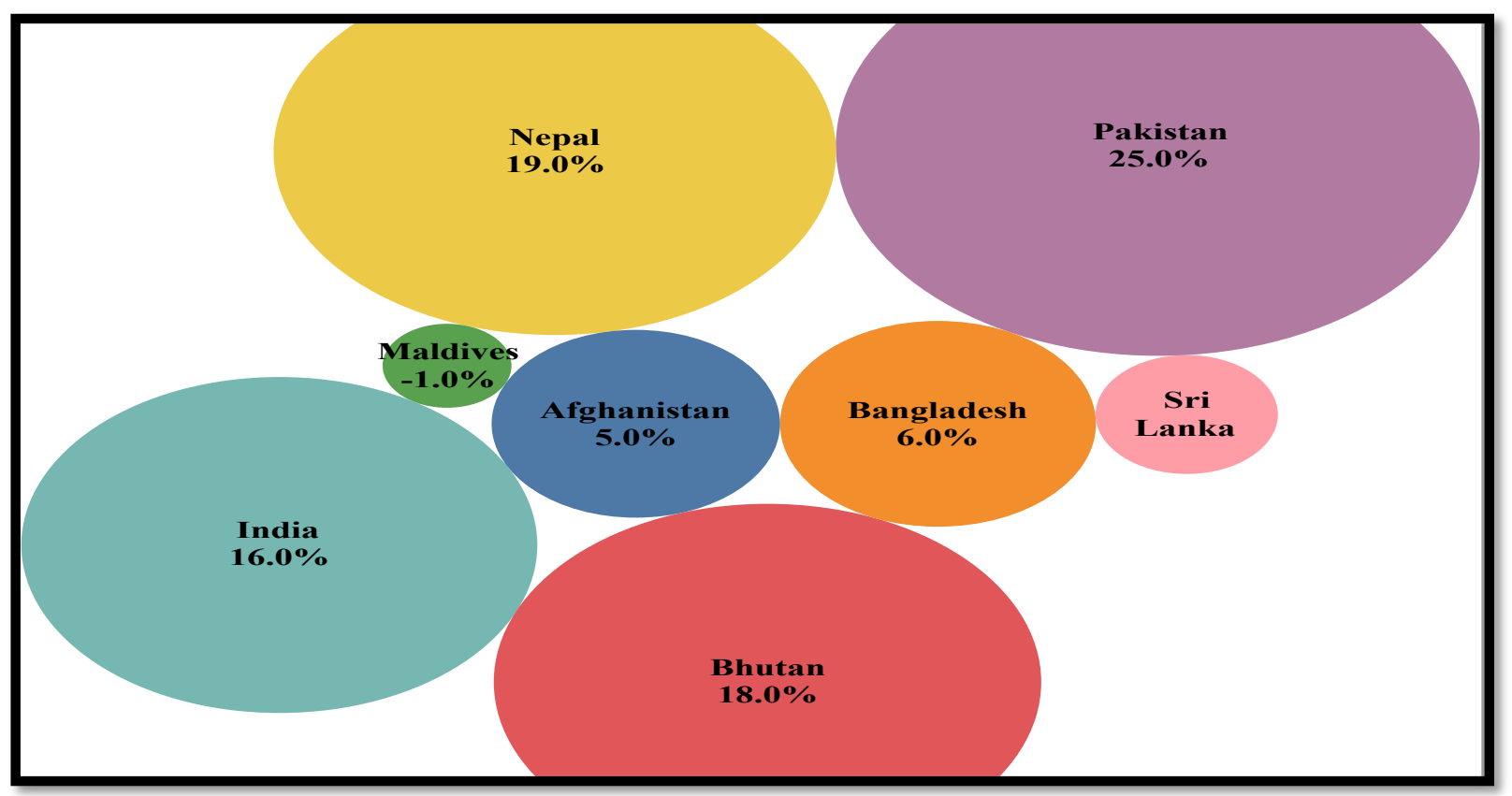

Source: World Bank Data, 2018

As the figure 4 showing that all the South Asian countries have a high percentage of educated persons with very less gender difference except for Nepal, Pakistan and India. Sri Lanka accounts to just 2 percent gender gap in education attainment whereas the Maldives witnessed more female literacy over males by showing the data in negative by -1 percent. The reason 
noticed behind fewer gender variance in these countries is easy accessibilities of education facilitates and socio-economic dynamics among both male and female. India is far behind these acceptable standards in accomplishing education with equality because of large regional disparities attributed to female candidates. Still, a large disproportionate share of the female is not going to school and even more prominent in poor families. Hence, statistics are sufficient to judge the hidden opportunity cost of engaging girls in unproductive works. Undoubtedly, education has a positive impact the gender development and increase the decision making power among individual but higher dropout rates can't be ignored while evaluating the gender gap. Abandoning girls from school contributes to a greater degree of gender inequality. Hence, it can be said that only though enrolment in higher attainment of education by a female can change the surroundings for them that is growing from a century on the name of tradition and cultural burden on them.

Figure 5: Gender Parity in India

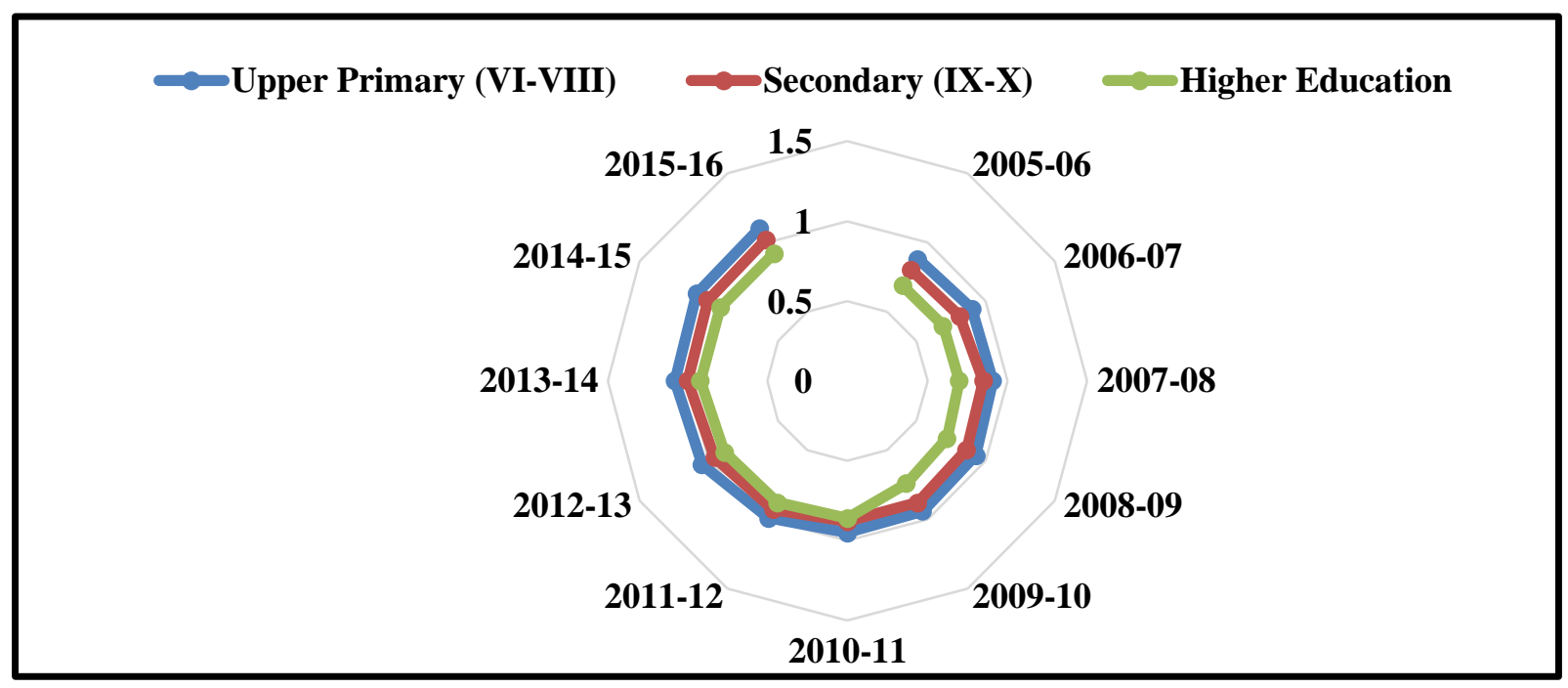

Source: Education Statistics at a Glance (2018) *Based on GER 
Figure 6: Education Expenditure in South Asian Countries to GDP and TE

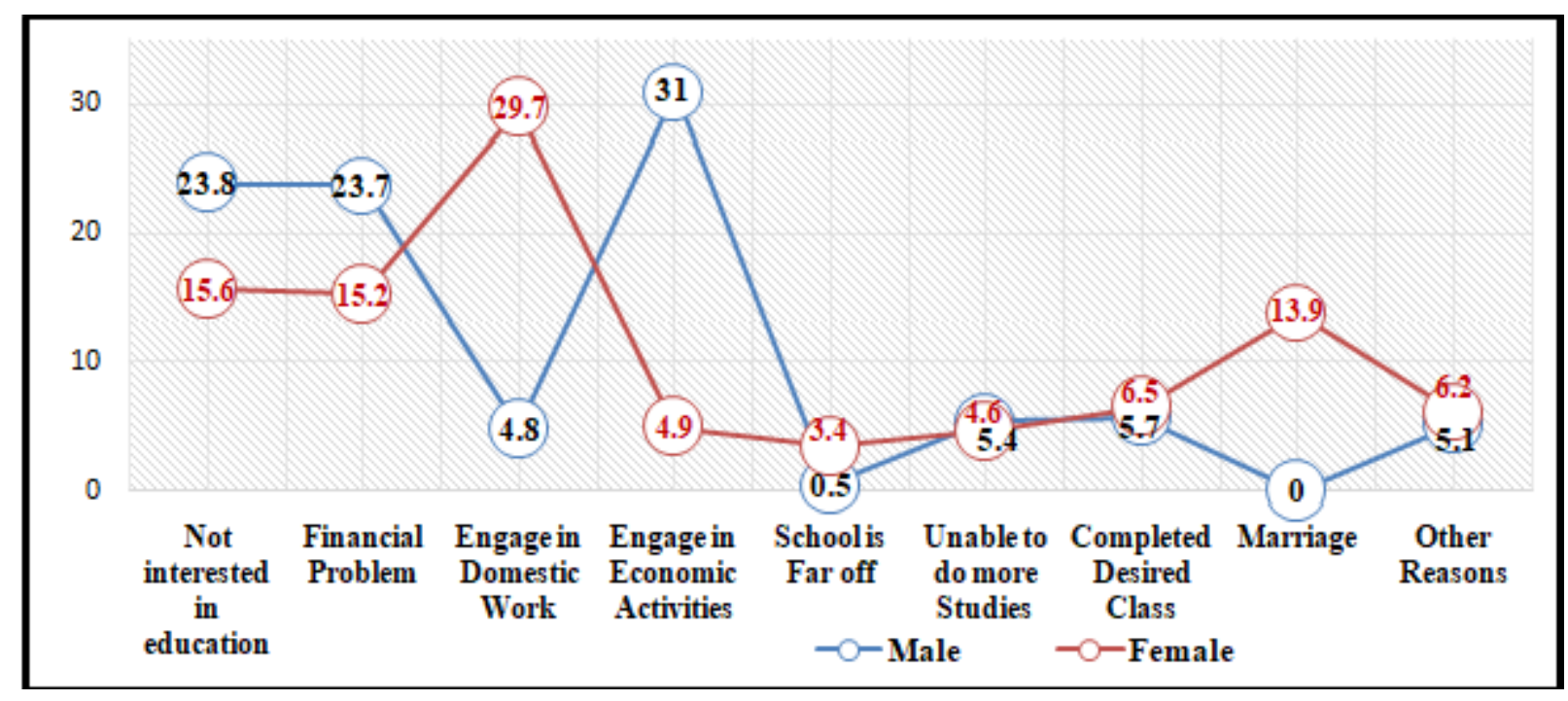

Source: Ministry of Human Resource and Development (2018)

The radar in the figure 5 depicting the overall performance of India over a decade. It can be easily seen that the gap between the genders in the education system is narrowing down as the year passes. The gender gap measured through the lines is shrinking when compared with the performance from 2005-06 to 2015-16. Gender parity at the upper primary is well noticeable and observes even more than unity, it means more girls are enrolling at the primary level than the boys. Whereas, same positive attitude is visible in the gender parity for secondary education level where parity has almost achieved by 2015-16. However, the utmost deviation is visible in the higher education parity index though the gap is reducing over time. As shown in figure 6 there are several factors that can promote drop-out rates among females There are 238 males (23\%) that are not interested in obtaining an education at all whereas there are 156 females $(15.6 \%)$ who don't want to continue their education further. This situation is more widespread in rural areas as compared to urban areas. But, things are diverse for women when it comes to household domestic work. There is abnormal drop-out among girls because of their high indulgence in domestic work which accounts to 5 times more than male counterparts. There are 29.7 percent females over just 4.8 percent of males that produce more hurdles in conquering education knowledge. The other major impediment noticed for females in getting an education is their marriage also. Whereas, contrary to it there is no data found on males' marriage as a problem in proceeding their further education. Apart from social and cultural attributes towards women, the far-away schools are also a major obstacle. So, in last it would not be wrong to say that there are so many evils factors associated with the girls education. Early marriages, non- 


\section{International Journal of Social Science and Economic Research}

ISSN: $2455-8834$

Volume:06, Issue:03 "March 2021"

viabilities of schools in their diameters and the burden of household work restrain female's capability to study more for their better and bright future.

\section{Female in Labour Force}

Persistence decline in the female labour force is a also a major obstacle faced by the Indian economy. Despite of increase in educational attainment in India among both male and female it is considered as one of the most pressing challenge. Irrespective of high standardised industrial and service sector expansion in the economy, female are facing unequal treatment and job security. They are unlikely to work in the recognised sector as the males do in society because of many cultural reasons. Their awfully indulgence in the unpaid care work for longer hours compared to men restrict their opportunities to work outside. Even if they do find work than they often discovered depress in term of payment. It is estimated by ILO (2018), that there are more than 70 percent of women who wants to work in the paid job but the multiplicity of the barrier is holding back them from realising their potential to work.

Women participation in the employment can help in reducing gender inequality, thereby empowering women and contributing to their capacity to exert choice and decision making power and agency in key domains in their lives (Desai, 1994, Kabeer 2012 and Chaudhary, 2014). But, simultaneously it is widely recognised that women's work in developing world is overlooked, undervalued and underreported because women are almost home-based and contributing to the non-market activities such as caregiving which have economic benefits to the households (Boserup, 1970 and Chaudhary, 2014). India is also experiencing the same despite of structural shifts in the economy. The country is moving towards higher education accomplishment over the last two decades but their participation in the labour force is declining over time. It has reduced to 27.21 percent in 2018 form 36.78 percent in 2004-05 which is far below the global world average (ILO 2018). India also witnessed the lowest women participation rate for among other peer countries because of the several factors like poor quality of education, their fertility rates, country economic development, access to childcare and other supportive services. Therefore, the below mentioned figure provide us a detail analysis of most emerging economies of the world i.e. South Asian countries. They collectively represent a high percentage of the world GDP but still, countries such as India and Pakistan have even less than 30 percent of its female labour. 
International Journal of Social Science and Economic Research

ISSN: 2455-8834

Volume:06, Issue:03 "March 2021"

Figure 7: Female Labour Force Participation in South Asia

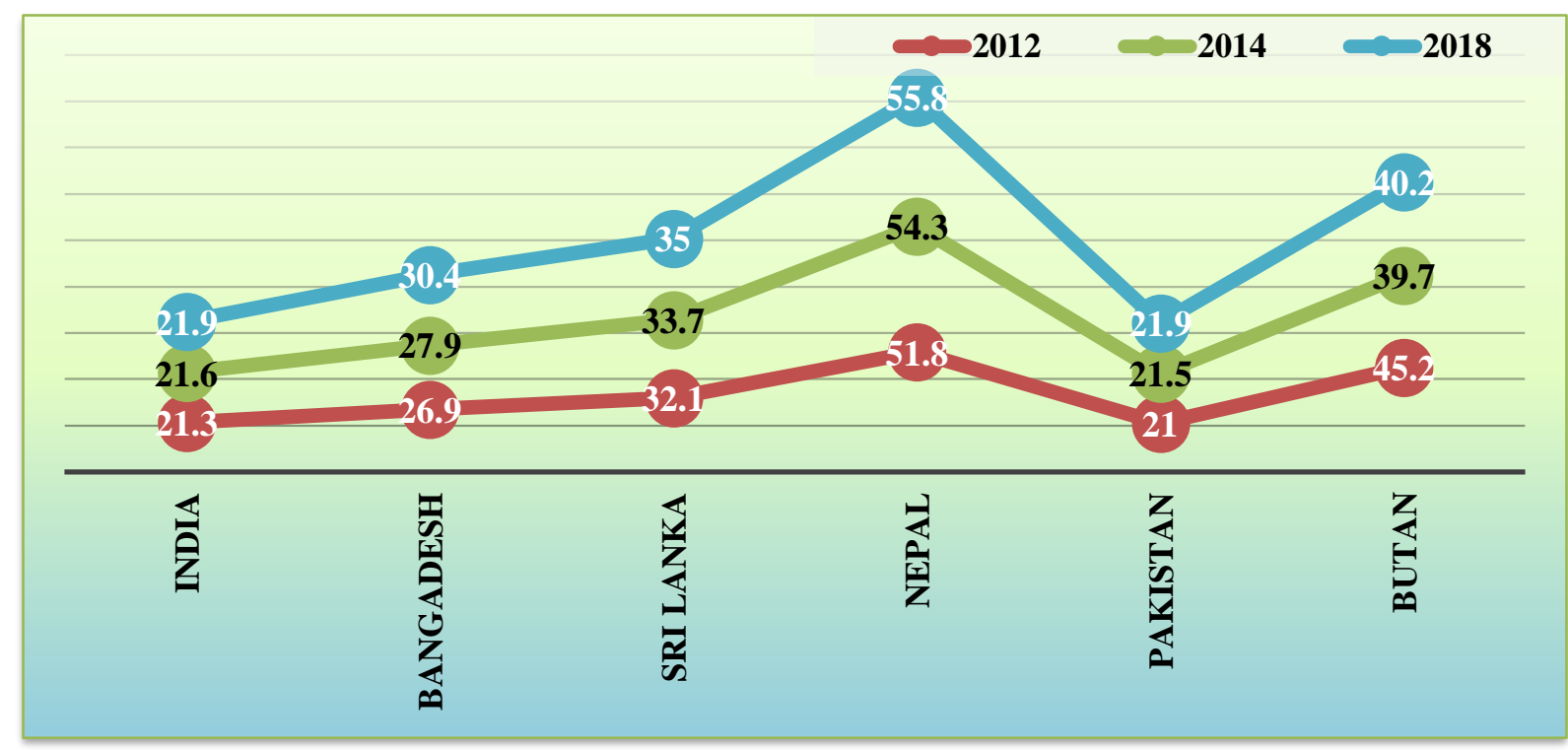

Source: World Bank (2018)

India accounts for 21.9 percent women participation rate followed by Pakistan with uniform proportion measured during 2018. However, the female participation rate in India has little crawled up from 21.3 in 2012 to 21.9 percent in 2018 but still extremely low among other South Asian Countries. Whereas, Nepal and Bhutan being a small and developing nation manifest 55.8 percent and 40.2 percent of the female labour force in 2018 with higher speed from the preceding years. India is presentation complex relationship between female labour force participation and economic development. This abnormal variation is a result of a difference in socio-economic attributes of a county like their level of education, fertility rate and the prevalence of gender difference. India is breaking universal law by demonstrating an inverse relationship between educational attainment and level of employment This explains about the poor cultural attributes towards inappropriate behaviour against girls which limits their choice to work outside. Some other constraint behind leaving the labour force among female is due to poor income growth, low quality work and lack of future growth offered to them. Because of such difference higher educated female might prefer luxury life and likes to devote their time in parenting and educating their children. 
International Journal of Social Science and Economic Research

ISSN: 2455-8834

Volume:06, Issue:03 "March 2021"

\section{Figure 8: Labour force Participation in India}

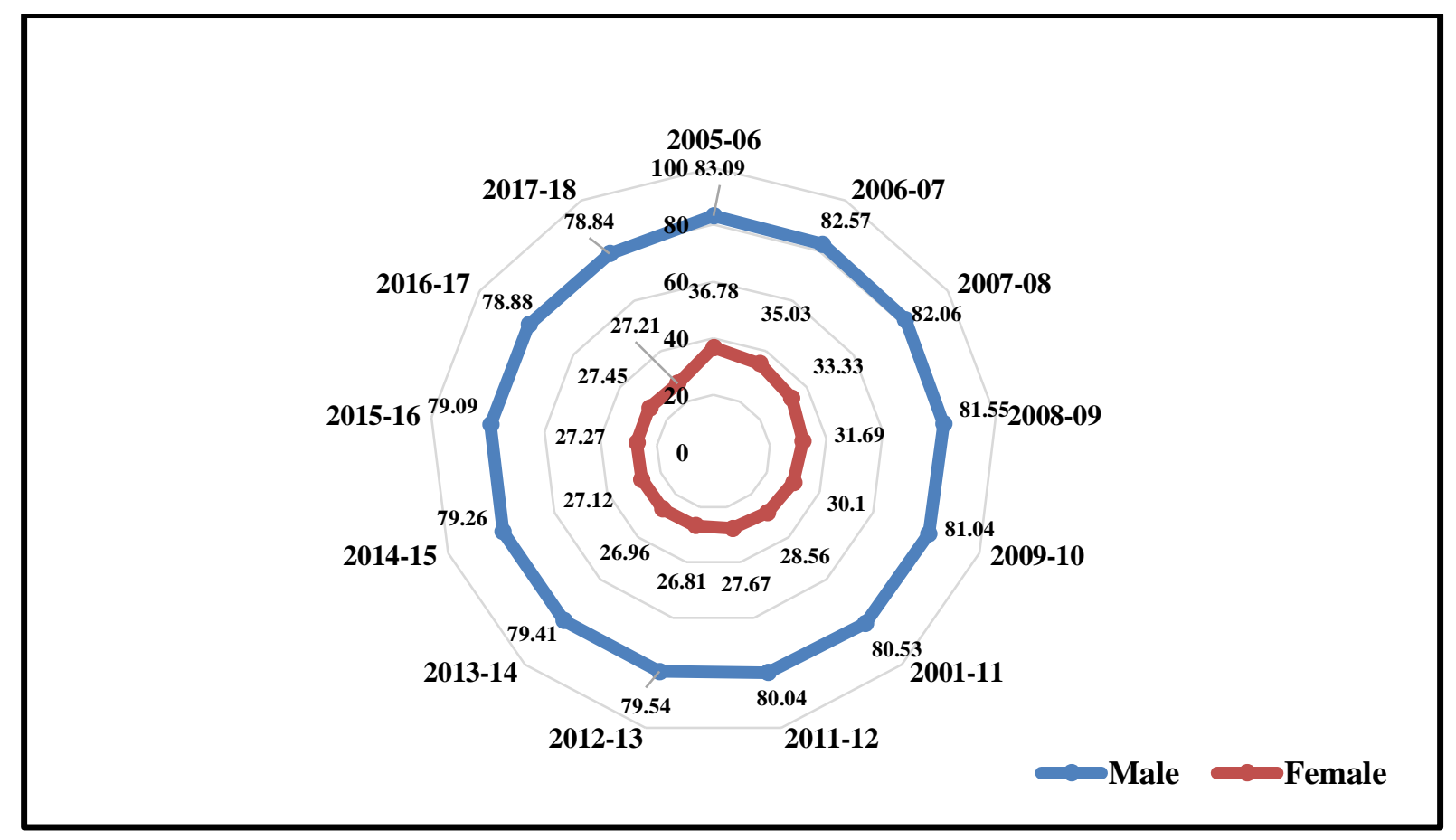

Source: ILO, 2018-19

After analysing India's position in South Asian countries the above figure 8 shows the trends of female labour force participation rate in India. Only $27 \%$ of Indian women are in labour force till the year 2017-18- the lowest among bricks nation and in G-20 countries. It shows a serious decline in the female participation rate over time from 36.78 percent in 2005-06 to 27.21 percent in 2017-18 as per the ILO report. Where on the one side nation is marking an improvement in certain areas of the elementary gender indicators (Health and Education sector) but on the other side it is struggling from tremendous fall-off among women from the workforce. India witness only one-third of the female population engage in paid work over male despite of high gender parity in education which devises major impediment for the government while framing policies. The nuclearization of families and household work being noticed a big reason behind such decline as lack of support from other family members. 
International Journal of Social Science and Economic Research

ISSN: 2455-8834

Volume:06, Issue:03 "March 2021"

Figure 9: Gender wise wage difference in India

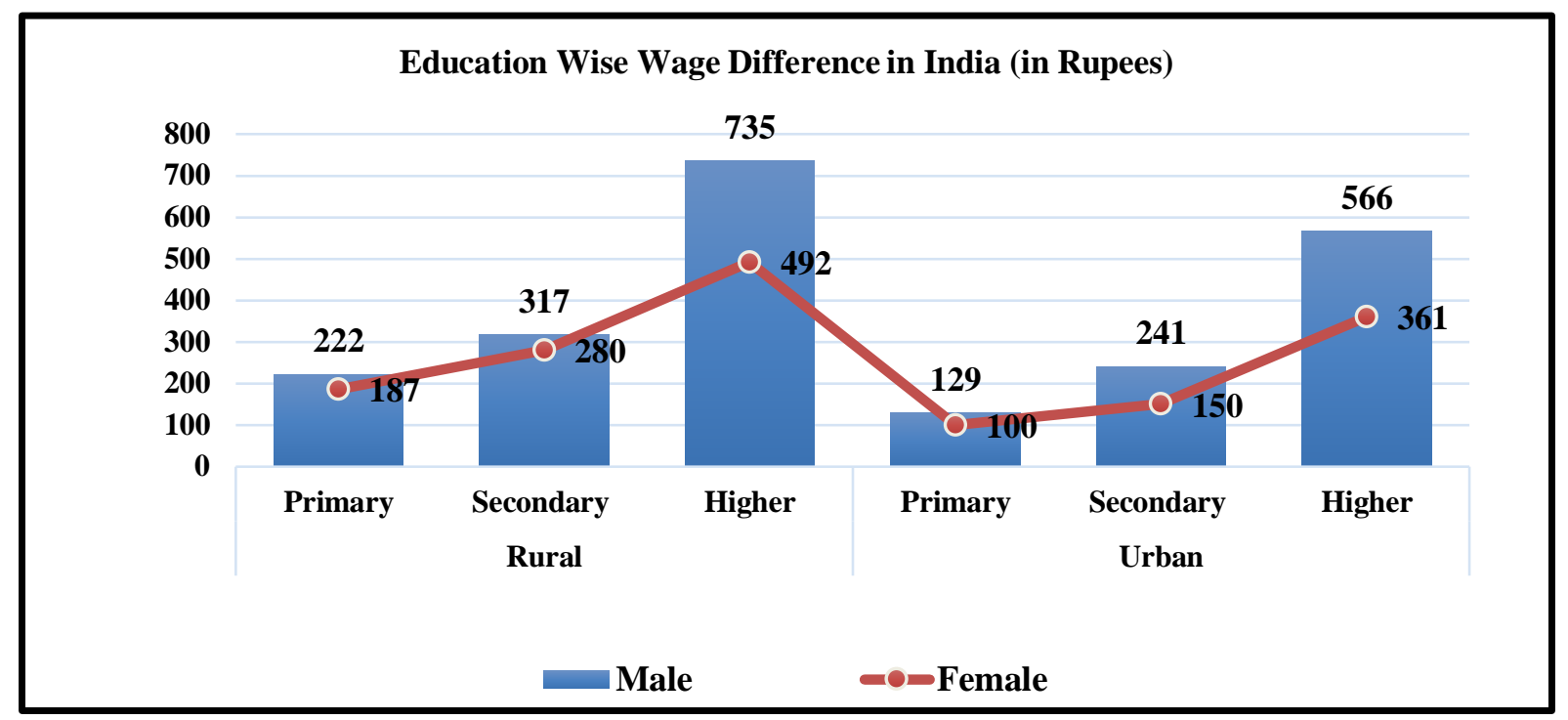

Source: Gender Pay Gap and ILO Estimates (2018)

Wage discrimination is also a major hurdle that restrict female economic participation. As it can see from above that wage difference is more pronounced among higher educated genders. Male obtains Rs. 735 whereas female receives Rs. 566 as an average wage per day for uniform work done by them. Which impacts their capabilities and willingness which in turn compensated by their reduced economic participation. Income effect has found one of the dampening effect causing more dropouts of females from the labour force. It also leads to a contradictory situation for India to analyse such situation and reconstruct a uniform environment for both genders. Moreover, it is also believed that the difference not only associated with the same level of educated gender but also in the form of average daily wages earnings of regular and casual work.

\section{Female in Political Participation}

Women are highly underrepresented in political participation, around only one-fourth of the female is the member of a national parliament worldwide. Lack of women representation is a crucial barrier to their decision making powers and their accountability. Whereas, it is important to ensure women's and men's equal participation in governance processes and the decision that affect their lives are vital for achieving inclusive and effective governance (UNDP, 2017). India is a worse performer and accounts to just 12 percent of the female participation rate in the Indian parliament. IMF (2015) also stated that despite of being India as the second largest most populous country have less than 30 percent of female economic participation indicating widest gender gap among G-20 economies. This could have a severe adverse effect on their knowledge, 
self-confidence and their voice. However, to combat such disproportion Indian government has started with female reservation policy at the local and national level but remained ineffective to target the concerns. The World Economic Form's in Global Gender Report (2014) highlighted the positive correlation between gender equality and per capita income, competitiveness and human development, which is visibly reducing in India.

\section{Figure: Female Parliamentary Representation among South Asian Countries}

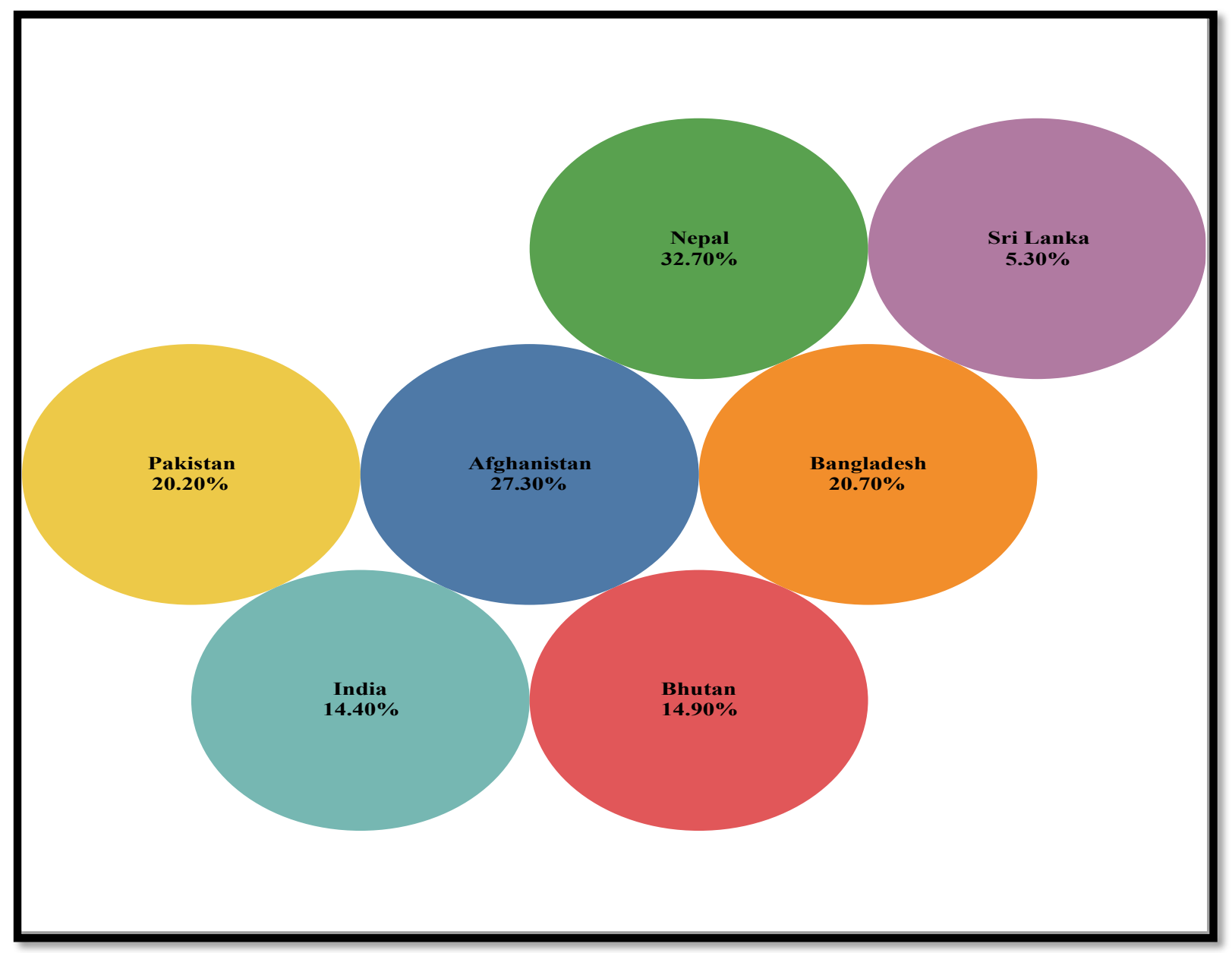

Source: Inter-Parliament Union 'Women in National Parliament', 2019

As it can be seen that Sri Lanka, India and Bhutan are the only South Asian countries with very less female parliamentary representation. Nepal surpasses the Index for women participation in Parliament with 32.7 percent representation rate in 2018-19 followed by Bangladesh and Pakistan also with 20.7 and 20.2 percent women representation for the same year. Nepal is the only South Asian country whose representation is above the world average in parliament 


\section{International Journal of Social Science and Economic Research}

ISSN: $2455-8834$

Volume:06, Issue:03 "March 2021"

(24.5\%), whereas India's share is quite below even encompassing nearly half of the world average. The low share of women in parliamentary is deeply embedded in the turbulent political Indian economy and accounts to just 14.4 percent share. There is no significant improvement found in the women average representation. It is contemplated that if they take active political participation they could have a better understanding of their problems to work upon. In the case of India, trends are quite worrying about representing weak and dependent factor on social elites. Cast based reservation apart from only reservation can prove beneficial to the country. Highly educated females of lower sub-cast have a higher potential to affect the people profile, reliability and their auxiliary exemplification also.

\section{Conclusion}

This paper scrutinized women status in health, education and labour force participation rate in India. These three measures are found extremely correlated with each other. Adverse health outcomes promote male skewed sex ratio as a result of orthodox culture and high desire for son in the families. High female child mortality rate and maternal mortality rate are more susceptible to death because of lack of care and their negligence from childhood itself. High preference for sons and undervaluation of daughter promotes more skewed investment in education also. India alone originated such country among all other South Asian countries that devised adverse female child sex ratio. However, lots of efforts were made by the Indian government to integrate gender equality in education and health sector to provide them better opportunities to stand equally with men. To meet this unfortunate gender health outcomes, India disburse only 3 percent of the country's GDP approximately on an average. Another problem observed is that a country largely relies on out of pocket expenditure to meet their health expenditure which makes it extra challenging for poor people to compress especially for female where they are dependent on others income. They found themselves helpless as dependent on their husband income or other family members which makes it additional puzzling to conquer health services, hence a large portion of population needs remains unmet. Regardless of high gender biases perceived in the health and education sector, gender gap realized even more prominent in economic participation. India found relatively tripped in a puzzling stage where despite the upsurge in education realization among females, their participation is deteriorating over time. It has become extremely tricky for the Indian government where achieving gender parity remain almost irrelevant if a female cannot enjoy the benefit of equal participation. This silence in expressing a negative correlation between education and labour force participation among females has become a paradox for the Indian government. India is one of the exceptional countries where female participation is declining over time despite of more educational enrolments and raising higher education level. There is a greater urge for the Indian government to pump huge investment for 
International Journal of Social Science and Economic Research

ISSN: 2455-8834

Volume:06, Issue:03 "March 2021"

gender development with the safest environment to work as a prerequisite for women development in distinctive parts within the country.

\section{References}

'Sen, A. (1989). Women's survival as a development problem. Bulletin of the American Academy of Arts and Sciences, 43(2), 14-29.

Alvaredo, F. Chancel, L. Piketty, T. Saez, E.\& Zucman, G. (Eds.). (2018). World inequality report 2018. Belknap Press.

Bhattacharya, S., Tiwari, K. K., Mohammad, T., Singh, D., Gautam, R. P., \& Rani, S. (2018). Educational statistics at a glance.

Blau, F. D., \& Kahn, L. M. (2000). Gender differences in pay. Journal of Economic perspectives, 14(4), 75-99.

Brush, C., Ali, A., Kelley, D., \& Greene, P. (2017). The influence of human capital factors and context on women's entrepreneurship: Which matters more? Journal of Business Venturing Insights, 8, 105-113.

Brynin, M. (2017). The gender pay gap. Equality and Human Rights Commission (EHRC).

Census of India (2001). Registrar General of India.

Davies, J. B., \& Zhang, J. (1995). Gender bias, investments in children, and bequests. International Economic Review, 795-818.

Ghosh, S. (2007). National family health survey-3 (2007). Indian pediatrics, 44(8), 619.

India, P. (2011). Census of India 2011 provisional population totals. New Delhi: Office of the Registrar General and Census Commissioner.

Joe, W., Mishra, U. S., \& Navaneetham, K. (2008). Health inequality in India: evidence from NFHS 3. Economic and Political Weekly, pp 41-47.

Mukhopadhyay, C., Shaw, T., Varghese, G. M., \& Dance, D. A. (2018). Melioidosis in South Asia (India, Nepal, Pakistan, Bhutan and Afghanistan). Tropical medicine and infectious disease, 3(2), 51. 
International Journal of Social Science and Economic Research

ISSN: 2455-8834

Volume:06, Issue:03 "March 2021"

NFI (2017)Gender Responsive Budgeting Basic Course Training of Trainers' (ToT) Manual for Civil Society Organisations.

Ortiz-Ospina, E., \& Roser, M. (2018). Economic inequality by gender. Our World in Data.

Sen, A., \& Anand, S. (1996). Gender Inequality in Human Development: Theories and Measurement. Background Papers: Human Development Report 1995.

Sen, A., (2003). Missing women-revisited. Appleby, J. (2018). The gender pay gap in the NHS. BMJ, 361.

Sen, A., (2003). Missing women-revisited. Appleby, J. (2018). The gender pay gap in the NHS. BMJ, 361.

Singh, D (2013). Effectiveness of Gender Budgeting for Women Empowerment: Evidence from India, Finance India, Vol. XXVII No. 4, December 2013, pp1263-1286

UNDP, U. (2018). Human development indices and indicators: 2018 statistical update.

Union, I. P. (2010). Women in National Parliaments (2012). Women in Parliaments: World and Regional Avarages", dal sito http://www. ipu. org/wmne/world. htm, 10.

Union, I. P. (2015). Women in national parliaments.

Verick, S. (2018). Female labor force participation and development. IZA World of Labor.

Vikash, V. (2019). Human Development Index and Gross National Happiness Indices: A Conceptual Study. Advances in Management, 12(1), 62-63.

World Bank (2011), 'World Development Report 2012: Gender Equality and Development.

World Bank, Washington D.C.

World Bank (2012), 'World Development Report 2013: Jobs', World Bank, Washington D.C.

World Bank. (2017). World development report 2018: Learning to realize education's promise. The World Bank.

World Bank. (2018). The World Bank Annual Report 2018. The World Bank.

World Bank. (2018). The World Bank Annual Report 2018. The World Bank. 
International Journal of Social Science and Economic Research

ISSN: 2455-8834

Volume:06, Issue:03 "March 2021"

World Economic Forum. (2017). The global gender gap report. Genebra: World Economic Forum. 